\title{
EL PRINCIPIO DE PARTICIPACION EN LAS LEYES DE SERVICIOS SOCIALES
}

\author{
Dr. RAFAEL BARRANCO VELA
}

Profesor de Derecho Administrativo

EUTS de la Universidad de Granada

\section{LA ADMINISTRACION PUBLICA, EL CIUDADANO Y LA PARTICIPACION}

\subsection{La vigencia y el concepto de participación}

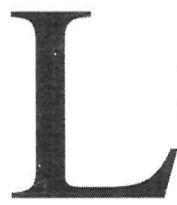

a participación es un tema que difícilmente pierde vigencia. El «derecho» a participar sirve igualmente para denunciar al sistema como para que éste se legitime. Reflejo de la importancia de este principio y del reciente desarrollo normativo de la acción social pública en España, son las frecuentes referencias a la participación en la legislación autonómica de los Servicios Sociales. Pero, además, la participación es principio inspirador de nuestro Ordenamiento y, al mismo tiempo, aspecto medular de la actividad administrativa de servicio público que es el sistema de Servicios Sociales.

Por otra parte, si bien ha existido una creciente participación del ciudadano en las funciones administrativas, se observa, al mismo tiempo, un alejamiento en el interés por participar o por la efectividad de esa participación.

Es más, se ha llegado a hablar de crisis en la participación ${ }^{1}$. Sin

1 Pérez Moreno ha señalado que «la participación administrativa en la primera década de vigencia de la Constitución Española de 1978 ha atravesado por una etapa de desorientación, es decir, de crisis». Las causas complejas que dan lugar a tan súbito decaimiento de la filosofía participativa - establece con posterioridad el autor - pueden concentrarse en un núcleo: el exceso de politización de la vida social. Es más, señala posteriormente, «para algunos autores la conquista del poder por ideologías que utilizaron la reivindicación participativa como instrumento ha determinado que se atrofien sus mecanismos» (cfr. «Crisis de la participación administrativa» en Actualidad y perspectivas del Derecho Público a fines del siglo XX. Homenaje al Profesor Garrido Falla, tomo I, Madrid, 1992). 
embargo, no podemos olvidar - y más en los momentos actuales- la transcendental importancia de la efectiva participación del ciudadano en la toma de decisiones y en la actividad de la Administración pública en general. En suma, la participación tiene un aspecto de reclamación constante, de exigencia por participar, de reivindicación. Pero no es menos cierto que los ciudadanos abandonamos con frecuencia las vías de la asociación, de la reclamación (que es una de las más importantes formas de participación), o la propia participación en la toma de decisiones. Aunque las trabas burocráticas, procedimentales o la escasa fuerza -o al menos eficacia y concreción- de los principios que amparan el derecho a participar, conviertan algunas iniciativas en reiteradas e inútiles tentativas, no podemos desdeñar que la perspectiva de que el problema va más allá: también falta una educación ciudadana en la participación y una exigencia y ejercicio efectiva de ésta ${ }^{2}$.

Por otra parte, la participación es un concepto, en definitiva, sujeto a multitud de interpretaciones ideológicas ${ }^{3}$, y por tanto de clara dificultad a la hora de establecer sobre el mismo unos parámetros definitorios sin que se corra el riesgo de establecer meros juicios de valor. Es más, la participación en sí, como afirma Sánchez Morón «constituye una ideología política-jurídica cuya pretensión es la de sustituir a la antigua idea-mito del interés general» ${ }^{4}$.

\subsection{El aspecto administrativo de la participación}

Nuestra visión de la participación se refiere a su aspecto administrativo. En este sentido, no es necesario recordar aquí -aunque con-

${ }^{2}$ Si bien es cierto que a la Administración compete, también, el fomento de la participación, nadie puede ser tan cándido de pensar que la Administración va a suplicar que el ciudadano participe en las decisiones, castigando la apatía versus premiando la participación.

${ }^{3}$ Refiriéndose al Estado Social y democracia, afirmaba García Pelayo (cfr. Las transformaciones del Estado contemporáneo, Alianza, 2. ${ }^{2}$ edición, pág. 46, Madrid, 1985), que «en cada coyuntura histórico-política hay unos vocablos cargados de prestigio que tendencias políticas diversas pueden tratar de atraer para sí, aunque ello sea contrario al sentido originario y a la formulación clara y distinta de sus conceptos». Y esto se produce, afirma este autor, citando a Freyer (Politische Grundbegriffe, Wiesbaden, 1951, pág. 3), que estos conceptos políticos, «sirven no sólo a la consideración, conocimiento y disposición teóricas, sino también a la vida, al deseo y a la acción políticas».

${ }^{4}$ Cfr. «El principio de participación en la Constitución Española», RAP, núm. 89, págs. 173-174, Madrid, 1979. Por otra parte, es ya conocida y reiteradamente citada la concepción de la llamada «ideología de la participación que realizó Chevallier (cfr., en este sentido, p. e., «La participation dans I'Administration francaise: discours et practique» en Revue d'Administration Publique, 1976, núms. 37 y 39). 
venga remarcarlo - la creciente intervención de la Administración en las diferentes esferas y actividades sociales. Esta creciente participación del Estado ${ }^{5}$ en la actividad social y económica en particular, no es ya tan siquiera una cuestión objeto de discusión según tendencias ideológicas. Es una realidad tangible en la vida cotidiana de cualquier ciudadano cada vez más dependiente, en un sentido u otro, del Estado y, por ende, de la Administración pública. Es por ello que la participación directa de los ciudadanos y de los grupos sociales no surge ya como el «necesario» principio legitimador del sistema, sino como una oportuna medida de eficacia de la decisión a adoptar y una necesidad de control de la actividad pública.

Dado por supuesto y conocido el aumento paulatino de la participación de los ciudadanos, especialmente a través del sistema electoral, hoy, nos resulta más relevante y decisivo, el aumento de la participación de los grupos de interés - de colectivos ciudadanos, por tanto- en los procesos de adopción de decisiones públicas. Por esto y por el incremento constante de intervención de la Administración en la vida de los ciudadanos, debemos de afirmar - como ya destacó García de Enterría- ${ }^{6}$ que el tema de la participación de los particulares en la vida administrativa es rigurosamente contemporáneo. El Estado y la propia Administración pública han de ser objeto y cauce de la participación, vía de expresión del ciudadano, y de instrumento eficaz para el logro del interés general.

Pero en relación a la Administración pública existen diferentes tipos de participación. Sánchez Morón ${ }^{7}$, ha distinguido la participación interna, que consiste en la intervención de los que trabajan en el seno de la Administración pública; la participación externa, que en su sentido más amplio se refiere a la intervención de los individuos y grupos sociales exteriores a la organización administrativa la colaboración técnica, el ejercicio privado de funciones públicas, las garantías de intervención del ciudadano en el procedimiento, la defensa de intereses colectivos y el control de funciones administrativas (proce-

5 Como bien señala la OCDE «durante la posguerra se produjo una expansión considerable tanto de la importancia como de la función del Estado. Aunque este crecimiento ha disminuido de forma significativa, salvo en los casos de reprivatización de industrias nacionalizadas. Cabe esperar que, en un futuro previsible, el Estado siga desempeñando una función primordial en las sociedades y en las economías de los países miembros de la OCDE» (cfr. el Informe de la OCDE, finalizado en el año 1987, y publicado en español bajo el título La Administración al Servicio del Público, 2. a edición, MAP, pág. 43, Madrid, 1991).

6 Cfr. García de Enterría, «Principios y modalidades de la participación ciudadana», Libro Homenaje a Villar Palasí, Madrid, 1989, págs. 437 y ss.

$7 \mathrm{Cfr}$., con independencia de otros trabajos de este autor sobre esta materia, cfr. La participación del ciudadano en la Administración pública, CEC, Madrid, 1981, págs. 102 y ss. 
dimental, consultiva, negociadora, orgánica, electoral directa, y la participación interorgánica). A esta detallada clasificación se podían añadir muchas otras perspectivas, lo que da una idea del carácter multiforme y plural del propio término participación. En este sentido, podíamos decir que todos los anteriores tipos de participación responden a una participación activa de los ciudadanos o de las Administraciones u órganos en la toma de decisión, pero existen otras formas de participación, no típicas, de tipo pasivo y de naturaleza impositiva, como pueden ser las prestaciones personales o económicas de los ciudadanos o de parte de estos (usuarios o interesados) a determinados servicios públicos.

Nosotros nos vamos a referir de forma especial a la llamada participación externa, no porque la interorgánica u otras formas de participación no tengan importancia en la actividad pública de los Servicios Sociales, sino porque la finalidad última del término participación dentro de la legislación de Servicios Sociales tiene sentido desde la implicación activa de los ciudadanos — tanto usuarios y/o clientes, como interesados-en la acción social.

\section{LA PARTICIPACION COMO PRINCIPIO Y MANDATO CONSTITUCIONAL}

\subsection{Planteamiento general}

Nuestra Constitución es una de las Normas Fundamentales que más énfasis ha puesto en recoger el principio de participación, y que con más detalle ha regulado el mismo. No podía ser de otra manera, dada la joven edad de nuestro Texto constitucional, el proceso histórico y el propio contexto socio-político del que surge, y, porque, precisamente, el pluralismo es piedra angular de nuestra Constitución.

La participación, en definitiva, no es más que una manifestación del principio - más genérico- del pluralismo, sin éste no existe posibilidad de participación, pues ningún sentido tiene predicar la participación cuando ésta queda vedada o restringida exclusivamente para algunos sectores sociales o a determinados grupos de interés. Nuestra Constitución tiene su origen no sólo en un proceso plural, sino que su contenido normativo se consolida tras largos acuerdos y debates, llegándose a una forma de consenso que, como pocas, implican la participación de todos los llamados en ese proceso constituyente.

Por otra parte, la participación, desde la perspectiva política, surge y tiene su sentido último, en gran medida, para llenar el vacío e insatisfacción que produce la democracia formal meramente representativa. Es el efecto legitimador al que nos referíamos con anterioridad. 
Con independencia de otras muchas citas ${ }^{8}$, en nuestra Constitución la participación se estructura básicamente en dos brazos: los partidos políticos y la de los ciudadanos y los grupos de interés (sindicatos, asociaciones empresariales, sectoriales, profesionales, etc.). Incluso podíamos decir que también son dos los artículos que marcan la pauta de esta división. De una parte el artículo $6 \mathrm{CE}^{9}$, con referencia a la participación de los partidos políticos, como forma institucional e instrumento de expresión del pluralismo político. Y de otra, que es ahora la que más nos interesa, el artículo 9 CE referido a la participación de los ciudadanos en la vida política, económica, cultural y social.

El artículo 9 no sólo marca el aspecto que más nos interesa desde el punto de vista de la participación ciudadana y los Servicios Sociales, sino que, probablemente, su contenido sea el más determinante en torno a la participación. Señala que «los ciudadanos y los poderes públicos están sujetos a la Constitución y al resto del ordenamiento jurídico», estableciendo con posterioridad, en su apartado segundo, que precisamente a los poderes públicos corresponde «promover las condiciones para que la libertad y la igualdad del individuo y de los grupos en que se integran sean reales y efectivas; remover los obstáculos que impidan o dificulten su plenitud y facilitar la participación de todos los ciudadanos en la vida política, económica, cultural y social». Después de esta declaración parece importante resaltar que no sólo la participación es un mero principio, sino un claro mandato a los poderes públicos para que faciliten (se podía haber mejorado este término) la participación de todos los ciudadanos (no ya usuarios o interesados, conceptos más restringidos), y de manera especial en cuatro campos específicos: la vida política ${ }^{10}$, económica, cultural y social.

${ }^{8}$ Existen otras muchas referencias constitucionales, con independencia de las que posteriormente vamos a tratar, al principio de participación o a otras formas de participación. Entre ellas podemos señalar entre las activas (en este caso desde aspectos internos e internos), la del artículo $27 \mathrm{CE}$, referida a la participación efectiva de todos los sectores afectados - una perspectiva más de los interesados- por el derecho a la educación; y, entre las que hemos denominado pasivas (en este caso de carácter interno), la del artículo $142 \mathrm{CE}$, que hace referencia a la participación — contribución- del Estado y las Comunidades Autónomas en la financiación de las Haciendas locales.

9 «Los partidos políticos expresan el pluralismo político, concurren a la formación y manifestación de la voluntad popular y son instrumento fundamental para la participación política. Su creación y el ejercicio de su actividad son libres dentro del respeto a la Constitución y a la ley. Su estructura interna y funcionamiento deberán ser democráticos».

10 Cauce, como otros, que hay que entender con independencia de los propios cauces institucionales como los partidos políticos. 
De todas formas - se aprecia a simple vista y sin que ello suponga restarle importancia - se puede observar que estamos ante una declaración programática sin apenas fuerza práctica. Los mismos términos en que se constriñe la declaración del artículo $9 \mathrm{CE}$ son de hecho vagos y poco determinantes. En este sentido, ya en los debates del Senado ${ }^{11}$, previos a la aprobación de la Constitución, se solicitó sustituir la palabra «promover» por la más efectiva de «establecer», y la de «remover» por la más contundente de «suprimir». De haberse modificado estos aspectos no se hubiera alterado el carácter programático del párrafo $2 .^{\circ}$ del artículo 9 , pero sí se habría conseguido un mayor grado de exigencia, con mayor amparo normativo, de cara a los poderes públicos.

2.2. Dos aspectos a destacar: la participación de la juventud, y la participación en la Seguridad Social y en organismos públicos con competencias en materia de Servicios Sociales

Una vez expuesto - aunque brevemente- el significado y contenido del artículo $9 \mathrm{CE}$, no se trata, en este momento, de hacer un análisis exhaustivo de ésta u otras citas a la participación, pero sí señalar dos aspectos específicos que nos interesan especialmente. Nos referimos a las referencias a la participación en los órganos de la Seguridad Social.

\section{a) La participación de la juventud}

Un apartado y mención concreta merece la referencia especial o al menos especialmente tipificada, con que la Constitución resalta, en su artículo 48, la participación libre y eficaz de la juventud: «Los poderes públicos promoverán las condiciones para la participación libre y eficaz de la juventud en el desarrollo político, social, económico y cultural». Entendemos que aquí no se pretende hacer una clasificación diferenciada de tipos de participación, la que afecta a la juventud y la que afecta a otros grupos de población, sino de resaltar el especial interés que la Constitución concede a la participación expresa de la juventud, garantía de legitimación y continuidad del sistema. Por otra parte, existen precedentes en menciones expresas a la participación de la juventud, tal como ocurre en el artículo 70 de la Constitución portuguesa.

"I Cfr. sobre estas propuestas los Diarios de Sesiones del Senado de 23 de agosto de 1978, págs. 1730 y ss., y el comentario a este artículo en Garrido Falla et al., Comentarios a la Constitución, Cívitas, Madrid, 1985, págs. 155 y ss. 
b) La participación en la Seguridad Social y en organismos públicos con competencias en materia de Servicios Sociales

El artículo 129.1 referido a las formas de participación de los interesados en la Seguridad Social, prescribe que «la Ley establecerá las formas de participación de los interesados en la Seguridad Social y en la actuación de los organismos públicos cuya función afecte directamente a la calidad de la vida o al bienestar general». Como se ha puesto de relieve por Jiménez-Blanco ${ }^{12}$, recogiendo la jurisprudencia del Tribunal Constitucional, del apartado primero de este artículo se desprende que «debe armonizarse el desarrollo con la calidad de vida» ${ }^{13}$, y que la «participación prevista en ese precepto lo es sólo para los organismos públicos y, no, por ejemplo, en Comisiones nacidas del Acuerdo Económico Social» ${ }^{14}$.

Para nosotros, la importancia de este artículo no reside en la referencia a la Seguridad Social, ya de por sí trascendente y que afecta claramente al área del bienestar social, sino en el posterior mandato de la obligada participación de los interesados en los organismos públicos cuya función afecte al bienestar general y la calidad de vida. En suma, en la medida que determinadas prestaciones sociales aún se siguen canalizando a través de la Seguridad Social, y, especialmente porque la segunda parte de este párrafo afecta de manera directa, problemamente sea la referencia más específica de la participación y del mandato participativo al sistema público de los Servicios Sociales.

\section{LA PARTICIPACION CIUDADANA EN EL AMBITO DE LA ADMINISTRACION LOCAL}

\subsection{El ámbito local como marco idóneo para la participación y la acción social}

El municipio y, en general, las entidades locales, parecen $-\mathrm{y}$ de hecho lo son- los ámbitos territoriales no sólo más racionalmente adecuados para la aplicación y el efectivo ejercicio de la participación de los grupos sociales y del administrado considerado individualmente, sino de participación concreta - tanto política como administrativa - del ciudadano en la Administración pública. Formas de participación directa del ciudadano en el ámbito municipal que, en algunos casos, incluso, aunque de forma muy atenuada y restringida,

12 Cfr. Comentario a la Constitución. La jurisprudencia del Tribunal Constitucional, comentario al artículo 129, pág. 730, CEURA, Madrid, 1993.

13 STC 64/1982, de 4 de noviembre.

14 STC 39/1986, de 31 de marzo. 
han existido en épocas de regímenes no democráticos, y que han dado lugar a instituciones de conocida y rancia tradición histórica española con famosas manifestaciones en el Medievo.

Si todo ello se puede predicar en el ámbito de la participación, ni que decir tiene que en el ámbito específico de los Servicios Sociales la instancia local no sólo ha servido como cauce de desarrollo de la acción social sino como el marco natural de su actuación ${ }^{15}$.

\subsection{La participación en la Ley de Bases de Régimen Local}

Por todo lo anterior, no es casual que la propia Ley $7 / 1985$, de 2 de abril, reguladora de las Bases del Régimen Local (LBRL), establezca en su Preámbulo que «la experiencia histórica demuestra de modo irrefutable que el florecimiento de la vida local presupone el disfrute de amplia autonomía nutrida por la participación auténtica de los vecinos». Es más, el propio artículo 1 LBRL, configura a los Municipios como «cauces inmediatos de participación ciudadana en los asuntos públicos, que institucionalizan y gestionan con autonomía los intereses propios de las correspondientes colectividades».

La participación, de esta manera, no sólo se concibe en la LBRL como un derecho ciudadano, sino, también como un deber. La participación es derecho y deber de los vecinos, que tienen, incluso, la obligación de participar en la gestión municipal de acuerdo con lo dispuesto en las Leyes y, en su caso, cuando la colaboración con carácter voluntario de los vecinos sea interesada por los órganos de gobierno y administración municipal (art. 18.1 LBRL).

Existen, con independencia de los artículos citados, gran número de citas a la participación ${ }^{16}$, pero quizá convenga ahora detenerse en

15 Sin embargo, si echamos una vista a nuestro pasado veremos que no ha sido así. Carmen Alemán (cfr. El Sistema Público de Servicios Sociales en España, Granada, 1991, pág. 209), lo ha puesto de manifiesto señalando que el hecho de que en España los Municipios no hayan sido «el medio natural para la prestación de servicios sociales» se ha debido a diferentes causas, que resumidamente, podríamos establecer en: la fuerte centralización, la escasez de recursos y la tendencia a la especialización, y la vinculación con la idea de «establecimiento» de los Servicios Sociales.

16 Pongamos algunos ejemplos relevantes:

- El artículo $27 \mathrm{LBRL}$ recoge expresamente que la «Administración del Estado, de las Comunidades Autónomas y otras entidades locales podrán delegar en los Municipios el ejercicio de competencias en materias que afecten a sus intereses propios, siempre que con ello se mejore la eficacia de la gestión pública y se alcance una mayor participación ciudadana».

- El artículo 70 establece que las sesiones del Pleno de las Corporaciones locales son públicas, que los acuerdos municipales deberán ser publicados y que 
dos aspectos consustanciales al tema que nos ocupa. Nos referimos a la participación de los ciudadanos en los órganos de gestión desconcentrada y las asociaciones de defensa de los intereses vecinales.

\subsection{Especial referencia a la participación en los órganos de gestión desconcentrada y en las Asociaciones de defensa de intereses vecinales}

\section{a) La participación en los órganos de gestión desconcentrada}

El artículo 24 LBRL se va a ocupar de regular los llamados, técnicamente, órganos de gestión desconcentrada y que habitualmente son conocidos como ayuntamientos de barrio ${ }^{17}$, si bien es verdad que el primer concepto respondería a una figura mucho más amplia que lo vulgarmente se viene a entender por lo segundo.

Precisamente el fundamento de la creación de estos órganos de gestión desconcentrada lo encuentra la LBRL en facilitar y mejorar la participación ciudadana en la gestión de los asuntos locales. Estos órganos desconcentrados y/o delegados del ayuntamiento, sin autonomía prevista (sin perjuicio de la unidad de gobierno y gestión del Municipio, afirma la LBRL), no son obligatorios ${ }^{18}$. El artículo, señala que los «municipios podrán establecer órganos territoriales de gestión desconcentrada, con la organización, funciones y competencias que cada Ayuntamiento les confiera». Sin embargo, cada vez estos órganos de gestión desconcentrada se muestran como los instrumentos más eficaces para acercar el gobierno a los vecinos y participar los ciudadanos en la gestión de su entorno.

\section{b) Las Asociaciones de defensa de los intereses vecinales}

No ha dejado, tampoco, la LBRL de tener en cuenta, como en el caso anterior de forma novedosa, las asociaciones de vecinos $u$ otras

todos los ciudadanos tienen derecho a obtener copias y certificaciones acreditativas de aquéllos.

- El artículo 71, por su parte, autoriza al Alcalde —en determinados casos y con autorización del Gobierno - a someter a consulta popular aquellos asuntos de la competencia propia municipal y de carácter local que sean de especial relevancia para los intereses de los vecinos.

17 Apelativo pionero en Italia y que ha tenido un desarrollo importante en este País (cfr. sobre estos aspectos: Sánchez Morón «Los Consejos de barrio en Italia: una experiencia de participación administrativa», $R E D A$, núm. 14, págs. 415-459, Madrid, 1977).

${ }^{18}$ Lo que se entiende perfectamente en municipios de reducida población o asentados sobre un único núcleo. 
de carácter más general que incidan en las competencias propias del municipio o que afecten, de una manera u otra, a los vecinos de determinada entidad local. El artículo $72 \mathrm{LBRL}$, establece que «las Corporaciones locales favorecen el desarrollo de las asociaciones para la defensa de los intereses generales o sectoriales de los vecinos, les facilitan la más amplia información sobre sus actividades y, dentro de sus posibilidades, el uso de los medios públicos y el acceso a las ayudas económicas para la realización de sus actividades e impulsan su participación en la gestión de la Corporación en los términos del número 2 del artículo 69. A tales efectos pueden ser declaradas de utilidad pública».

Como se puede apreciar del contenido de este artículo, se establece una clara división entre las asociaciones de intereses sectoriales y otras de intereses más amplios. En las primeras son donde se incluyen, entendemos que adecuadamente, las asociaciones de vecinos.

El problema de su ineficacia viene derivado no sólo de la excesiva politización, sino que, principalmente, a través de ésta, las asociaciones de vecinos dejan de ser el cauce de reivindicación y colaboración sectorial, para convertirse en «células» de cultivo, colaboración o de formación de determinadas opciones políticas, y transformarse, sin necesidad de perder su forma, en vías de reclamación de intereses generales o diferentes a los particulares para las que se constituyen. La importancia de los intereses sectoriales es que éstos lo sean de forma pura e interesada. Verdaderamente libres e interesados, diríamos, y que con ello agrupen por el efecto de la contradicción, un colectivo de intereses que sumados en lo atendible y lo rechazable se llegue a un interés común, cercano al interés general, que no es exactamente el interés social, pero sí una buen parte de éste.

Diferentes son las iniciativas en orden a dotar de competencias expresas a las asociaciones vecinales ${ }^{19}$, donde existan funciones garantizadas y vías públicas de participación. Ese es, por ejemplo, el reciente protocolo de colaboración firmado entre la Federación Andaluza de Municipios (FAMP) y la Confederación de Asociaciones de Vecinos de Andalucía (CAVA), que supone la materialización de campañas de divulgación de derechos de los vecinos, establecimiento

19 No exentas, todavía, de una excesiva politización. Y por ello no pretendemos hacer cantos de sirena a las Asociaciones de Vecinos sin más y de forma genérica, cuando, es conocido, que gran parte de ellas tienen como contenido sustancial la organización de las «fiestas del barrio» subvencionadas, a veces, en mayor o menos medida en función de las afinidades políticas y con los impuestos del resto de los ciudadanos. En estos casos - afortunadamente en contra de otras iniciativas serias y participativas que no participadas - efectuar una sinonimia de la participación urbana con las asociaciones de vecinos, es sólo una burla al principio de participación y una burda mueca al de solidaridad. 
de vías de diálogo e información mutuas, y acciones concretas como el Teléfono de los Vecinos.

En suma, la importancia de las asociaciones de vecinos desde el aspecto de la participación resulta manifiesta. Es más, pensamos que están absolutamente desaprovechadas las posibilidades de actuación de dichas asociaciones en el ámbito de la acción social, si bien, hay que decir, que loables actuaciones particulares de los profesionales del Trabajo Social y otras más esporádicas de la Administración están modificando esta cuestión.

Lo que ocurre es que la proliferación de centros urbanos, de verdaderas metrópolis, hace necesario, no ya unos cauces conformados y diseñados para la participación, sino la aparición de otras vías que satisfagan demandas ciudadanas, o supongan alternativas para otro tipo de exigencias, especialmente aquéllas que no encuentran respuesta por los circuitos institucionales establecidos, o las que buscan una solución sectorial adecuada a sus reivindicaciones particulares.

No estamos hablando de otra cuestión más que de los llamados movimientos ciudadanos, sociales, o urbanos. Las funciones o tipología de estos movimientos es ilimitada ${ }^{20}$. J. Borja ${ }^{21}$ distingue la siguiente tipología de movimientos populares urbanos:

- Movimiento generado por el deterioro importante y súbito de las condiciones de vida.

- Movimiento generado por la amenaza que representa la acción urbanística.

- Movimiento generado por un déficit constante de vivienda o servicios.

- Movimiento de oposición a la política urbana de la Administración.

Para nosotros, la anterior clasificación es absolutamente aleatoria y con evidentes signos de politización, pero, sirve, sin embargo, de forma adecuada para marcar unos ámbitos de actuación claramente definidos en la actualidad. En cualquier caso, parece claro que los Movimientos sociales son aquellos que surgen de forma espontánea en la sociedad civil, a la que es - cada día - más acuciante retornar. Es probable, y antes lo poníamos de manifiesto, que se corra el peligro de politizar en exceso éstas, en origen, verdaderas iniciativas so-

${ }^{20}$ Llamar, por ejemplo, a los squatters movimiento social y no hacerlo con una «unión» de arrendatarios o comuneros o propietarios, incluso hacerlo con los que rechazan los abrigos de pieles, y no con amantes de las mariposas o de los sellos, no sólo es de una miopía flagrante y de una visión ideologizada y partidista, sino intrínsecamente absurda.

${ }^{21}$ Por unos municipios democráticos. Diez años de reflexión política y movimiento ciudadano, IEAL, Madrid, 1986, págs. 22-25. 
ciales de participación ciudadana, con el consiguiente desencanto y desenganche de amplios sectores sociales. Es curioso observar cómo, a veces y fruto de la miopía política de los que padecen esta contagiosa enfermedad, no se incluyan específicamente dentro de estos movimientos sociales a los grupos de voluntariado en la acción social, cuya importancia y desarrollo en otros países ha sido tan determinante que de manera efectiva descargan o compaginan con el Estado - que no por eso está exento de sus obligaciones y de garantizar las prestaciones - la actividad prestacional de servicio público o bien la gestionan directamente con los consiguientes controles administrativos ${ }^{22}$, en una verdadera opción voluntaria de participación ciudadana.

\section{LA PARTICIPACION COMO PRINCIPIO GENERAL DE LOS SERVICIOS SOCIALES}

\subsection{El reflejo de la participación en la Administración prestacional}

En el tema de la participación y la Administración prestacional surge, de inmediato, la idea de la gestión directa de esta actividad administrativa de servicio público. Lo cierto es que la gestión directa de los servicios públicos ha sido un tema propuesto y discutido con la misma intensidad. En general, la alternativa que supone esta forma de participación directa por los ciudadanos o por parte interesada de ellos, siendo interesante no está exenta —al menos en la actualidad y en la configuración de nuestra Administración pública- de dificultad por su aplicación restringida. Pero, precisamente en ciertos niveles de la Administración asistencial y cultural pueden darse importantes pasos hacia adelante en esta dirección.

La participación es sin duda alguna uno de los principios que han marcado el proceso de institucionalización de los servicios sociales y ha estado presente desde el primer momento de la normatización - $y$ por tanto, establecimiento de garantías - de éstos. Buena prueba de ello es que, ya en 1961, la Carta Social Europea, en su artículo 14.2, referido al ejercicio efectivo del derecho al beneficio de los servicios sociales, establece que los Estados contratantes se comprometen a:

22 Incluso, como afirma García de Enterría, una cierta intervención o inspección administrativa en su funcionamiento, «para evitar la desnaturalización de sus fines altruistas en otros egoístas, y la eventualidad de una descalificación si tales fines o las garantías de que su gestión se rodea se frustrase» (cfr. García de Enterría, E. y Fernández, T. R., Curso de Derecho administrativo, 2 vols., 5 . $^{\mathrm{y}} \mathrm{y}$ 4. a edición, respectivamente, Cívitas, Madrid, 1993, pág. 96). 
«alentar la participación de los individuos y de las organizaciones benéficas, u otras, en la creación o el mantenimiento de esos servicios».

En España, y a partir de la entrada en vigor de la Constitución española, se acelera este proceso institucional y normativo de los Servicios Sociales. Especialmente, con la atribución de competencias exclusivas en la materia a las Comunidades Autónomas. Precisamente el marco jurídico básico de estos nuevos entes político territoriales no tarda en recoger esta perspectiva participativa de los Servicios Sociales. Y aunque de forma directa la atribución de competencia en la materia viene marcada por frases cortas y concisas, no ocurre así en los textos estatutarios, cuando, se trata de materias conexas, como la de entidades prestacionales como la Seguridad Social, tal como vimos en el artículo 129 de la Constitución española. Así, por ejemplo, el artículo 20.5 del Estatuto de Autonomía para Andalucía ${ }^{23}$, señala que «la Comunidad Autónoma de Andalucía ajustará al ejercicio de las competencias que asuma en materia de Sanidad y Seguridad Social a criterios de participación democrática de todos los interesados, ...». Cuestión que se repite en iguales términos en el EA de la Comunidad Valenciana ${ }^{24}$ y en los demás Estatutos de Autonomía de las CCAA con competencia en la materia ${ }^{25}$.

Siguiendo con esta paulatina progresión y regulación de los servicios sociales, merece hacer mención de otro momento crucial para éstos, como es la creación de un Ministerio específico para el área de asuntos sociales. Nuevamente aquí va a aparecer de forma determinante la participación ${ }^{26}$.

Pero va a ser el desarrollo legislativo autonómico, en el que inmediatamente vamos a entrar, el que de manera definitiva realce la par-

${ }^{23}$ Ley Orgánica 6/1981, de 30 de diciembre.

${ }^{24}$ Ley Orgánica 5/1992, de 1 de julio.

${ }^{25}$ En este sentido, por ejemplo, el artículo 17 del Estatuto de Autonomía de Cataluña, o el artículo 18 del Estatuto de Autonomía del País Vasco.

${ }^{26}$ El Real Decreto 727/1988, de 11 de julio, en uso de la autorización otorgada al Presidente del Gobierno por la disposición final séptima de la Ley 33/1987, de 23 de diciembre, crea el Ministerio de Asuntos Sociales y determina la competencia y funciones que se le atribuyen. En su artículo $10^{\circ}$ señala como funciones específicas del Ministerio:

(...)

b) Protección y fomento de las condiciones que posibiliten la igualdad social de ambos sexos, y la participación de la mujer en la vida política, cultural, económica y social.

(...)

d) Promoción de la comunicación cultural entre la juventud de España, el fomento del asociacionismo juvenil y de su participación en movimientos asociativos internacionales; al desarrollo y coordinación de un sistema de información y documentación de la juventud, y el fomento de las relaciones y de la cooperación internacional en materia de juventud. 
ticipación, como principio y pieza fundamental de los servicios sociales.

\subsection{Formas de participación en las Leyes Autonómicas de Servi- cios Sociales}

Las Leyes de Servicios Sociales van a regular la distribución de competencias, reservándose las Administraciones autonómicas las funciones de planificación, coordinación, supervisión y control, y las Corporaciones locales la gestión, ejecución y desarrollo de los servicios, siendo por tanto muy importantes las funciones de los Ayuntamientos y Diputaciones en los servicios como lugar más próximos al ciudadano ${ }^{27}$. Es por tanto en estos ámbitos locales - como ya establecíamos anteriormente- donde mayores perspectivas de participación en el sistema de acción social tiene el usuario y el interesado en los Servicios Sociales.

No obstante, las referencias a la participación en las diecisiete leyes autonómicas de Servicios Sociales son muy numerosas y no se limitan a los aspectos de la gestión y ejecución. La participación aparece, en primer lugar, como principio inspirador de los Servicios Sociales, afectando - dependiendo de los casos-a la promoción, intervención, control o el propio diseño de la acción social, y regulándose en conjunto o separadamente del resto de los principios generales ${ }^{28}$. En este sentido, el artículo 2.4 de la Ley $2 / 1988$, de 4 de abril, de Servicios Sociales de Andalucía, va a establecer que el sistema de Servicios Sociales se inspira en: ..., la participación, «mediante la intervención de los ciudadanos y usuarios, a través de los

27 Cfr. en este sentido el «Prólogo» de la edición conjunta que preparé con la Profesora Alemán Bracho, Legislación Básica sobre Servicios Sociales, Madrid, Tecnos, 1993.

28 Que podríamos resumir en:

1. Universalidad, atención a todos.

2. Igualdad, sin discriminación.

3. Solidaridad, justa distribución de recursos.

4. Prevención, eliminar causas de marginación.

5. Responsabilidad pública, recursos públicos.

6. Descentralización, acercar las instituciones más al ciudadano.

7. Normalización e Integración, cauces normales respetando el medio.

8. Participación, intervención de los ciudadanos en el control de los Servicios Sociales.

9. Planificación y Coordinación, equilibrio recursos y necesidades y armonización pública y privada.

10. Globalidad, consideración total de la persona y de los grupos y no sólo de aspectos parciales.

(Cfr. idem, Alemán y Barranco, págs. 28 y 29). 
cauces adecuados, en la promoción y control de los Servicios Sociales».

Por su parte el artículo 3, apartado 1.4 de la Ley de la Generalidad Valenciana 5/1989, de 6 de julio, de Servicios Sociales de la Comunidad Valenciana, establece que los «Poderes públicos promoverán la participación democrática de los ciudadanos en la planificación, gestión y control de las actuaciones»; y así sucesivamente el resto de las Leyes Autonómicas de Servicios Sociales ${ }^{29}$.

Otro aspecto más concreto e interesante de la participación es el que viene determinado por la participación de los usuarios, beneficiarios o interesados ${ }^{30}$. Con referencia al primer caso, el de los usuarios, el artículo 17.5 de la Ley andaluza va a establecer que la Administración autonómica determinará los criterios generales para la participación de los usuarios; por su parte, el artículo 13 de esta misma Ley, con referencia al funcionamiento de los Centros, va a establecer que el funcionamiento de éstos deberá ajustarse de tal manera que permita la participación de los usuarios. Existen otras referencias a los usuarios (caso, por ejemplo, del art. 14.6 de la Ley de Baleares, en relación al coste de los servicios el art. 14.6; o menciones más genéricas como las existentes en las Exposiciones de Motivos de las Leyes de Castilla-La Mancha, y Castilla-León).

Aunque hay otras y variadas llamadas a la participación (desde la Seguridad Social, Comisiones, Comunidades, ámbitos sectoriales, etc.), no queremos dejar de mencionar la participación del voluntariado y/o de entidades privadas. En este punto, nuevamente, las leyes van a repartirse el nominativo, pero, en conjunto, estimamos que la regulación parece escasa y excesivamente cautelosa. Nadie discutiría la participación del voluntariado, que no es algo anecdótico, ni la mera aplicación de un principio, sino, prácticamente, parte del siste-

29 Que se van a referir en términos parecidos, a uno u otro caso. Así, el artículo 3.e) de la Ley Aragonesa, el artículo 3.g) de la Ley Asturiana, el artículo 6.d) de la Ley de Baleares, el artículo 1.2.h) de la Ley Canaria, el artículo 3.e) de la Ley Cántabra, el artículo 3.2 de la Ley Castellano-Manchega, la Exposición de Motivos, en su apartado H), de la Ley Castellano-Leonesa, el artículo 3.f) de la Ley Catalana, el artículo 3.7 de la Ley Extremeña, el artículo 3.8 de la Ley Gallega, el artículo 3.3 de la Ley de La Rioja, el artículo 3.8 de la Ley Madrileña, el artículo 6.8 de la Ley Murciana, el artículo 2.f) de la Ley Navarra; y, por último, el artículo 5.3 de la Ley Vasca.

30 Términos, que como bien es conocido, no son idénticos, y que sin embargo son mencionados sin precisión técnica e incluso con equivocidad, en la legislación en la materia. A la participación de los beneficiarios se va a referir la Ley de Murcia (art. 37), y la del País Vasco y la Comunidad Valenciana en sus respectivas Exposiciones de Motivos. A la participación de los interesados, se refiere, por ejemplo, la Ley aragonesa, en su artículo 30 . 
ma de la prestación. Por otra parte, la vía de entidades, fundaciones, sociedades, etc., sin espíritu de lucro y prestadoras de Servicios Sociales, como vía propia del asociacionismo y, por tanto, como plasmación más patente de la participación ciudadana son la mejor vía para demostrar ese espíritu participativo. Sin embargo, también es verdad que, y ya tuve ocasión de manifestarlo ${ }^{31}$, el asociacionismo en España, desgraciadamente en muchos aspectos y por lo que tiene de negativo para los intereses y derechos ciudadanos, está aún lejos de ser una realidad que brota espontáneamente del tejido social.

Sin duda alguna la mayor concreción del principio de participación y su vertiente más activa, e incluso, diríamos, eficaz, viene determinada por la intervención directa o mediante representantes de los usuarios e interesados en los llamados Consejos Autonómicos ${ }^{32}$. A estos habría que añadir los Consejos Locales, ámbito más cercano para los usuarios, y prácticamente existentes en todas las Comunidades Autónomas. Nuevamente, estos Consejos Locales van a responder a los diferentes nombres de esa «trilogía» habitual en la materia: Servicio Social, Acción Social, y Bienstar Social ${ }^{33}$. Por último, existen toda una serie de Consejos de carácter especial ${ }^{34}$ o sectorial ${ }^{35}$.

\subsection{Una crítica valoración final}

Conviene, para terminar, hacer una valoración crítica. Así y tal como hemos podido comprobar de este pequeño análisis de la parti-

${ }^{31}$ Cfr. mi trabajo «Análisis del marco jurídico general de los Colegios Profesionales y las profesiones en España como premisa a una necesaria regulación del ejercicio profesional colectivo» en El ejercicio en grupo de profesiones liberales, Universidad de Granada, Granada, 1993, pág. 626.

${ }^{32}$ Con la denominación de Consejo... de Servicios Sociales, nos encontramos con el caso de Andalucía (art. 24), Castilla-La Mancha (art. 18), Galicia (art. 40), Canarias (art. 16), y Cataluña (art. 14); con la denominación de Consejo ...de Bienestar Social, en Aragón (arts. 33 y ss.), Asturias (art. 18), en La Rioja (art. 26.3), en Madrid (art. 18), en el País Vasco (arts. 16 y ss.), y en Valencia (arts. 19 y ss.); y, con el apelativo de "Acción Social», en Cantabria (art. 18), Castilla-León (art. 20), y Baleares (arts. 26 y ss.).

${ }^{33}$ Consejos Locales de Acción Social, existen en Baleares, Cantabria y Castilla-León; Consejos Locales de Bienestar Social, en Aragón, Asturias, La Rioja, Madrid, País Vasco, o Valencia; y, Consejos Locales de Servicios Sociales, en Andalucía, Canarias, Castilla-La Mancha, Cataluña, Extremadura, Galicia, Murcia y Navarra.

${ }_{34}$ Como son los Consejos Insulares, previstos en las respectivas legislaciones de Baleares y Canarias; o los Consejos Rurales y de Barrios, a los que se refiere la Ley de Castilla-León en su artículo 23.

${ }^{35}$ Como por ejemplo los previstos en los artículos 85 y 86 de la Ley $8 / 1985$, de 9 de diciembre, de Servicios Sociales de la Región de Murcia. 
cipación en la legislación autonómica de Servicios Sociales, diríamos que el principio de participación viene recogido con profusión y en lugar destacado dentro de las diferentes normas, pero pese a la importancia con que es tratado y la trascendencia que, en definitiva, tiene para la acción social, su regulación adolece de una mayor concreción. Se peca, en suma, de un excesivo principialismo ${ }^{36}$, acompañado - todo hay que decirlo- de falta de rigor terminológica, por un uso abusivo de expresiones vacías o de conceptos jurídicos indeterminados. Junto a esto se echa en falta un procedimiento ${ }^{37}$ administrativo propio que encauce la participación de los usuarios. Cierto es que las críticas anteriores se ven atenuadas por la existencia de los Consejos (regionales, comarcales, locales o, incluso, de barrio) de los Servicios Sociales, pero, siendo esto positivo, dichos órganos administrativos de carácter consultivo y asesor carecen de la agilidad suficiente para que realmente se dé una participación efectiva. Al unísono de todo ello, existe una excesiva politización general del contenido normativo que, lógicamente, afecta también a la participación, con una sensación de «quiero y no puedo» que no puede dejar satisfecho al usuario ni al profesional, y que supone que la participación sea un concepto que, aun exigible, queda con frecuencia al arbitrio - como tantas otras veces - de la interpretación del político o la Administración de turno.

36 La excesiva retórica y alusión reiterada a los principios, puede llegar a que —no sólo en el ámbito de los Servicios Sociales - de la famosa Partizipationeuphorie de Schmidt-Glaeser (cfr. «Partizipation an Verwaltungsentscheidmugen» en Veröffentlichungen der Verenigneng der Deutschen Staatsrechtslherer, Helft, núm. 31, Berlín, 1973), pasemos a la «participación-fobia», y ciertas actitudes, no con dosis de razón, que desconfían y rechazan participar en determinaciones o acciones de carácter común, pueden responder a este anunciado cambio.

37 Téngase en cuenta que el procedimiento es una de las más efectivas garantías de participación. La reciente Ley 30/1992, de 26 de noviembre, Régimen Jurídico de las Administraciones Públicas y Procedimiento Administrativo Común, es un buen ejemplo de esto. En su propia Exposición de Motivos se recoge que «la evolución más reciente de nuestra organización administrativa hacia fórmulas participativas, obliga a contemplar la nueva tipología de órganos colegiados cuya composición y funcionalidad no se ajusta a la regulación establecida por la anterior Ley, dictada en una circunstancia histórica y política en la que la participación de otras Administraciones o de organizaciones sociales, resultaba impensable». 


\section{BIBLIOGRAFIA CITADA}

Alemán, C.: El Sistema Público de Servicios Sociales en España, Granada, 1991.

Alemán Bracho, C. y Barranco Vela, R.: Legislación Básica sobre Servicios Sociales. Tecnos, Madrid, 1993.

Barranco Vela, R.: «Análisis del marco jurídico general de los Colegios Profesionales y las profesiones en España como premisa a una necesaria regulación del ejercicio profesional colectivo». El ejercicio en grupo de profesiones liberales, Universidad de Granada, Granada, 1993.

Borja, J.: Por unos municipios democráticos. Diez años de reflexión política y movimiento ciudadano. IEAL, Madrid, 1986.

Chevallier, J.: «La participation dans l'Administration francaise: discours et practique». Revue d'Administration Publique, 1976, núms. 37 y 39.

Freyer, H.: Politische Grundbegriffe, Wiesbaden, 1951.

Garrido Falla et al.: Comentarios a la Constitución. Cívitas, Madrid, 1985, págs. 155 y ss.

García de Enterría, E.: «Principios y modalidades de la participación ciudadana». Libro Homenaje a Villar Palasí, Madrid, 1989.

García de Enterría, E. y Fernández, T. R.: Curso de Derecho administrativo. Cívitas, 2 vols., 5. ${ }^{\mathrm{a}}$ y 4. ${ }^{\mathrm{a}}$ edición, respectivamente, Madrid, 1993.

García Pelayo, M.: Las transformaciones del Estado contemporáneo. Alianza, 2.a edición, pág. 46, Madrid, 1985.

Jiménez-Blanco, A. et al.: Comentario a la Constitución. La jurisprudencia del Tribunal Constitucional. CEURA, Madrid, 1993.

OCDE: La Administración al Servicio del Público. MAP, 2. ${ }^{a}$ edición, pág. 43, Madrid, 1991.

Pérez Moreno, A.: «Crisis de la participación administrativa». Actualidad y perspectivas del Derecho Público a fines del siglo XX. Homenaje al Profesor Garrido Falla, tomo I, Madrid, 1992.

Sánchez Morón, M.: «Los Consejos de barrio en Italia: una experiencia de participación administrativa». REDA, núm. 14, págs. 415-459, Madrid, 1977.

-: «El principio de participación en la Constitución Española». RAP, núm. 89, págs. 173-174, Madrid, 1979.

-: La participación del ciudadano en la Administración pública. CEC, págs. 102 y ss., Madrid, 1981.

Schmitt-Glaeser, W.: «Partizipation an Verwaltungsentscheidmugen». Veröffentlichungen der Verenigneng der Deutschen Staatsrechtslherer, Helft, núm. 31, Berlín, 1973. 